\title{
Thirty-Day Prevalence ofDSM-IVMental Disorders Among Nondeployed Soldiers in the US Army
}

\section{Citation}

Kessler, Ronald C., Steven G. Heeringa, Murray B. Stein, Lisa J. Colpe, Carol S. Fullerton, Irving Hwang, James A. Naifeh, et al. 2014. "Thirty-Day Prevalence ofDSM-IVMental Disorders Among Nondeployed Soldiers in the US Army." JAMA Psychiatry 71 (5) (May 1): 504. doi:10.1001/ jamapsychiatry.2014.28.

\section{Published Version}

doi:10.1001/jamapsychiatry.2014.28

\section{Permanent link}

http://nrs.harvard.edu/urn-3:HUL.InstRepos:33839677

\section{Terms of Use}

This article was downloaded from Harvard University's DASH repository, and is made available under the terms and conditions applicable to Other Posted Material, as set forth at http:// nrs.harvard.edu/urn-3:HUL.InstRepos:dash.current.terms-of-use\#LAA

\section{Share Your Story}

The Harvard community has made this article openly available.

Please share how this access benefits you. Submit a story.

\section{Accessibility}




\section{Thirty-Day Prevalence of DSM-IV Mental Disorders Among Nondeployed Soldiers in the US Army Results From the Army Study to Assess Risk and Resilience in Servicemembers (Army STARRS)}

Ronald C. Kessler, PhD; Steven G. Heeringa, PhD; Murray B. Stein, MD, MPH; Lisa J. Colpe, PhD, MPH; Carol S. Fullerton, PhD; Irving Hwang, MA; James A. Naifeh, PhD; Matthew K. Nock, PhD; Maria Petukhova, PhD; Nancy A. Sampson, BA; Michael Schoenbaum, PhD; Alan M. Zaslavsky, PhD; Robert J. Ursano, MD; for the Army STARRS Collaborators

IMPORTANCE Although high rates of current mental disorder are known to exist in the US Army, little is known about the proportions of these disorders that had onsets prior to enlistment.

OBJECTIVE To estimate the proportions of 30-day DSM-IV mental disorders among nondeployed US Army personnel with first onsets prior to enlistment and the extent which role impairments associated with 30-day disorders differ depending on whether the disorders had pre- vs post-enlistment onsets.

DESIGN, SETTING, AND PARTICIPANTS A representative sample of 5428 soldiers participating in the Army Study to Assess Risk and Resilience in Servicemembers completed self-administered questionnaires and consented to linkage of questionnaire responses with administrative records.

MAIN OUTCOMES AND MEASURES Thirty-day DSM-IV internalizing (major depressive, bipolar, generalized anxiety, panic, and posttraumatic stress) and externalizing (attention-deficit/ hyperactivity, intermittent explosive, alcohol/drug) disorders were assessed with validated self-report scales. Age at onset was assessed retrospectively. Role impairment was assessed with a modified Sheehan Disability Scale.

RESULTS A total of $25.1 \%$ of respondents met criteria for any 30 -day disorder ( $15.0 \%$ internalizing; $18.4 \%$ externalizing) and $11.1 \%$ for multiple disorders. A total of $76.6 \%$ of cases reported pre-enlistment age at onset of at least one 30 -day disorder (49.6\% internalizing; $81.7 \%$ externalizing). Also, $12.8 \%$ of respondents reported severe role impairment. Controlling for sociodemographic and Army career correlates, which were broadly consistent with other studies, 30-day disorders with pre-enlistment $\left(\chi_{8}^{2}=131.8, P<.001\right)$ and post-enlistment $\left(\chi_{7}^{2}=123.8, P<.001\right)$ ages at onset both significantly predicted severe role impairment, although pre-enlistment disorders were more consistent powerful predictors (7 of 8 disorders significant; odds ratios, 1.6-11.4) than post-enlistment disorders ( 5 of 7 disorders significant; odds ratios, 1.5-7.7). Population-attributable risk proportions of severe role impairment were $21.7 \%$ for pre-enlistment disorders, $24.3 \%$ for post-enlistment disorders, and $43.4 \%$ for all disorders.

CONCLUSIONS AND RELEVANCE Interventions to limit accession or increase resilience of new soldiers with pre-enlistment mental disorders might reduce prevalence and impairments of mental disorders in the US Army.

JAMA Psychiatry. 2014;71(5):504-513. doi:10.1001/jamapsychiatry.2014.28 Published online March 3, 2014.
Editorial page 487

$\leftarrow$ Reto

Related articles pages 493 and 514
Author Affiliations: Author affiliations are listed at the end of this article.

Group Information: The Army Study to Assess Risk and Resilience in Servicemembers (Army STARRS) collaborators are listed at the end of the article.

Corresponding Author: Ronald C. Kessler, PhD, Department of Health Care Policy, Harvard Medical School, 180 Longwood Ave, Boston, MA O2115 (ncs@hcp.med.harvard.edu). 
$\mathrm{M}$ ental disorders are leading causes of US military morbidity. ${ }^{1}$ Indeed, health care visits and days out of role owing to mental disorders in the US military are exceeded only by those owing to injuries. ${ }^{2}$ This is partly because selection and retention criteria lead to low rates of chronic physical disorders, but military service also has unique stressors that can increase mental disorders. ${ }^{3-6}$ Annual hospital bed days owing to mental disorders in the US military doubled ${ }^{7}$ between 2006 and 2010 . The military suicide rate also increased substantially during this period. ${ }^{8}$ Although these trends are widely believed to be linked to the protracted conflicts in Afghanistan and Iraq, 3,9 it is not clear how many of these cases represented recurrences of pre-enlistment disorders. This question is important given recent discussions of optimal recruitment-retention strategies for an all-volunteer Army during times of war. ${ }^{10,11}$ We know from general population epidemiological studies that most lifetime mental disorders have childhood-adolescence onsets ${ }^{12-14}$ that are initially too mild to cause rejection from military service, even if they predict more severe subsequent episodes. ${ }^{15}$ We are unaware of previous research that has examined the question of pre-enlistment history of mental disorders. Such data are presented here from the Army Study to Assess Risk and Resilience in Servicemembers (Army STARRS; www.armystarrs.org), a large multicomponent epidemiological-neurobiological study of Army suicide. ${ }^{16}$

\section{Methods}

\section{The Sample}

Data came from the April to December 2011 Army STARRS AllArmy Study (AAS), a de-identified cross-sectional survey of active duty soldiers exclusive of those in Basic Combat Training or deployed to a combat theater. Quarterly AAS replicates consisted of stratified (by Army Command location) probability samples of units or subunits selected with probabilities proportional to authorized unit strength excluding units of fewer than 30 soldiers (less than $2 \%$ of Army personnel). All personnel in selected units were ordered to attend an informed consent presentation explaining study purposes, confidentiality, and voluntary participation before requesting written informed consent for a group self-administered questionnaire to link their administrative records to questionnaire responses and to participate in future data collections. Identifying information (eg, name and social security number) was collected from consenting respondents and kept in a separate secure file. These recruitment, consent, and data protection procedures were approved by the Human Subjects Committees of the Uniformed Services University of the Health Sciences for the Henry M. Jackson Foundation (the primary grantee), the Institute for Social Research at the University of Michigan (the organization collecting the data), and all other collaborating organizations.

A total of 327 group sessions were held in April to December 2011. Sessions were held with platoons (typically 30-60 soldiers), companies (typically 80-225 soldiers), or other subunits of battalions (typically 300-1300 soldiers, but divided into smaller groups for group administration). The median number of attendees was 18 (range, 1-169; interquartile range [ie, 25th-75th percentiles], 4-46). Small sessions were mostly held in medical or military police units to deal with their special 24hour operation schedules. Large sessions were confined to installations with large auditoriums and a short time window for unit data collection. All interview sessions were scheduled for 90 minutes.

The 5428 AAS respondents considered here represent all Regular Army soldiers in the April to December 2011 AAS who completed the questionnaire and provided written consent for administrative data linkage. Activated Army Reserve and National Guard respondents were excluded owing to small numbers. Although all unit members were ordered to report to informed consent sessions, $23.5 \%$ were absent owing to conflicting duty assignments. Most attendees in 2011 (96.0\%) consented to the survey, $98.0 \%$ of consenters completed the survey, and $69.2 \%$ of completers provided record linkage. Most incomplete surveys were owing to logistical complications (eg, units either arriving late or having to leave the 90-minute sessions early), although some respondents needed more than the allotted time to complete the survey. The survey completion-successful linkage cooperation rate was $65.1 \%(0.96 \times 0.98 \times 0.692)$ and the response rate was $49.8 \%$ ([1 - 0.235] $\times 0.651$ ) based on the American Association of Public Opinion Research COOP1 and RR1 calculation methods. ${ }^{17}$ Although we were prohibited from attempting refusal conversion or obtaining individual-level administrative data for refusers, de-identified administrative data were provided for the entire Army and for survey respondents who agreed to linkage, allowing 2 weights to be created to adjust for nonresponse bias. Weight 1 adjusted for discrepancies in survey responses between survey completers with and without record linkage. Weight 2 adjusted for discrepancies between multivariate administrative record profiles of weighted (weight 1) survey completers with record linkage and the target population. Doubly weighted (weight $1 \times$ weight 2 ) data were used in analyses. A more detailed description of AAS weighting is presented elsewhere. ${ }^{18}$

\section{Measures}

\section{Data Collection Mode}

Some data collection staff members were stationed throughout the field period at the largest 6 domestic Army installations (Forts Bliss and Hood in Texas, Bragg in North Carolina, Campbell in Kentucky, Carson in Colorado, and JB LewisMcChord in Washington; together accounting for $63.5 \%$ of the AAS sample). Other staff traveled to smaller installations. Questionnaires were computer-administered using laptop computers at the 6 largest installations, while paper and pencil administration was used at other facilities. A discussion of considerations in this dual-mode approach to data collection is presented elsewhere. ${ }^{19}$

\section{Diagnostic Assessment}

Respondents self-administered the Composite International Diagnostic Interview Screening Scale (CIDI-SC) ${ }^{20}$ and the Posttraumatic Stress Disorder (PTSD) Checklist (PCL) ${ }^{21}$ to assess 
30-day DSM-IV mental disorders. We distinguished between internalizing and externalizing disorders based on empirical evidence for the importance of this distinction. ${ }^{22}$ Internalizing disorders included major depressive disorder (MDD), bipolar I and II or subthreshold bipolar disorder, generalized anxiety disorder (GAD), panic disorder (PD), and PTSD. Externalizing disorders included attention-deficit/hyperactivity disorder (ADHD), intermittent explosive disorder (IED), and substance use disorder (SUD; alcohol or drug abuse or dependence). The SUD assessment included both illicit drugs and misused prescription drugs (the latter was defined as use either without a doctor's prescription; more than prescribed; or to get high, buzzed, or numbed out) based on evidence that prescription drug misuse is considerably more common than illicit drug use in the Army. ${ }^{23}$ All disorders were assessed without DSM-IV diagnostic hierarchy or organic exclusion rules. Respondents who reported a disorder were asked at what age they first experienced the disorder. Comparison of these age at onset (AAO) reports with respondent age at enlistment was used to distinguish disorders with pre- vs post-enlistment onsets. An AAS clinical reappraisal study found good individuallevel concordance (area under the receiver operating characteristic curve of 0.69-0.79 across diagnoses) ${ }^{24}$ between diagnoses based on the CIDI-SC or PCL and independent clinical diagnoses based on blinded administration of the Structured Clinical Interview for $D S M-I V .{ }^{25}$ The clinical reappraisal study also found that CIDI-SC and PCL prevalence estimates were unbiased relative to the Structured Clinical Interview for $D S M-I V$ prevalence estimates $\left(\chi_{1}^{2}=0.0-0.6, P=.89\right.$ to .43$) .{ }^{24}$

Health-Related Role Impairment

The severity of health-related role impairment was assessed with a revised version of the Sheehan Disability Scale ${ }^{26}$ asking respondents the extent to which problems with physical health, mental health, or alcohol-drug use interfered with their functioning in the past 30 days in each of 4 role domains using a 0 to 10 visual analogue scale labeled as no interference (0), mild (1-3), moderate (4-6), severe (7-9), and very severe (10) interference. The 4 domains were home management, quality of work on duty, social life, and close personal relationships. Severe self-reported role impairment was defined as a 7 to 10 rating in 1 or more domains.

\section{Sociodemographic and Army Career Variables}

Sociodemographic variables considered here included respondent sex, race/ethnicity, and marital status. Army career variables included rank, age at enlistment, number of deployments to a combat theater, and current Army Command assignment (the major organizational subdivisions within the Army). Race and ethnicity were assessed in 2 questions, the first asking respondents whether they were Spanish, Hispanic, or Latino (yes or no) and the second asking respondents to record their race by checking all applicable categories of white, black or African American, American Indian or Native American, Asian (eg, Chinese, Filipino, or Indian), and Native Hawaiian or other Pacific Islander and/or providing an open-ended response to an other race category. Responses were collapsed into the summary categories of non-Hispanic black,
non-Hispanic white, Hispanic, and others. Race and ethnicity were assessed as part of an effort to create a comprehensive sociodemographic profile of soldiers. Distributions of sociodemographic and career variables in the weighted AAS sample are quite comparable with those in the target population (Table 1).

\section{Analysis Methods}

Thirty-day prevalence of disorders with pre- and postenlistment AAO were compared with estimates from a subsample of the National Comorbidity Survey Replication (NCS-R), ${ }^{27}$ a US national household survey that assessed DSM-IV disorders with the full CIDI, ${ }^{20}$ calibrated to be sociodemographically comparable with the AAS using methods described elsewhere. ${ }^{28}$ Predicted age at enlistment was imputed at the individual level to NCS-R respondents using the SAS PROC MI procedure, ${ }^{29}$ which implemented Rubin's multiple imputation method ${ }^{30}$ using all variables available in both the NCS-R and Army administrative data set to make imputations. Logistic regression analysis was used to examine associations of sociodemographic and Army career variables with disorders and of disorders with self-reported severe role impairment. Coefficients were exponentiated to generate odds ratios (ORs) and 95\% CIs. Simulation methods described elsewhere ${ }^{31}$ were used to calculate population-attributable risk proportions (PARPs) of severe role impairment owing to 30day DSM-IV disorders with pre- vs post-enlistment AAOs. The PARP describes the proportion of observed severe impairment associated with the predictors. ${ }^{32}$ As the AAS data are both clustered and weighted, the design-based Taylor series linearization method was used to estimate standard errors. The significance of predictor sets was evaluated using design-based Wald $\chi^{2}$ tests. Statistical significance was evaluated using .05level 2-sided tests.

\section{Results}

\section{Prevalence of 30-Day DSM-IV Disorders}

Estimated 30-day prevalence was $15.0 \%$ for any internalizing disorder, $18.4 \%$ for any externalizing disorder, and $25.1 \%$ for any disorder (Table 2). The most prevalent disorders were IED (11.2\%), PTSD (8.6\%), and ADHD (7.0\%), with other disorders much less common (3.3\%-5.7\%). All AAS prevalence estimates were higher than in the calibrated NCS-R civilian sample (5.3\% any internalizing, $7.3 \%$ any externalizing, and $11.6 \%$ any disorder).

Nearly half (49.6\%) of AAS respondents with 30-day internalizing disorders had first onsets of at least 1 disorder prior to enlistment. Disorder-specific proportions of preenlistment onset are significantly lower in the AAS than calibrated NCS-R for each internalizing disorder other than PTSD $\left(X_{1}^{2}=7.3-10.9, P=.005\right.$ to .017$)$. Panic disorder and PTSD are the only 2 internalizing disorders where 30-day prevalence with pre-enlistment onset differs significantly between the AAS and NCS-R. Prevalence was higher in both cases in the AAS than NCS-R (PD: $1.0 \%$ vs $0.4 \%, X_{1}^{2}=4.4, P=.04$; PTSD: $2.6 \%$ vs 0.1 , $\left.\mathrm{X}_{1}^{2}=68.2, P<.001\right)$. 
Table 1. Distributions of Sociodemographic and Army Career Variables in Quarters 2 Through 4 of the 2011 Army STARRS All-Army Survey Analysis Sample and the Target Population of All Comparable US Army Personnel ${ }^{a}$

\begin{tabular}{|c|c|c|c|}
\hline \multirow[b]{2}{*}{ Characteristic } & \multicolumn{2}{|c|}{ Sample, \% (SE) } & \multirow[b]{2}{*}{ Population, \% } \\
\hline & Unweighted & Weighted & \\
\hline \multicolumn{4}{|l|}{ Sex } \\
\hline Men & $89.7(0.9)^{\mathrm{b}}$ & $85.9(0.8)$ & 85.8 \\
\hline Women & $10.3(0.9)^{\mathrm{b}}$ & $14.1(0.8)$ & 14.2 \\
\hline \multicolumn{4}{|l|}{ Race/ethnicity } \\
\hline Non-Hispanic white & $66.7(0.9)^{b}$ & $62.5(1.2)$ & 61.4 \\
\hline Non-Hispanic black & $15.8(0.7)^{\mathrm{b}}$ & $19.5(1.1)$ & 20.5 \\
\hline Hispanic & $11.1(0.5)$ & $11.0(0.5)$ & 11.1 \\
\hline Other & $6.4(0.3)$ & $7.1(0.5)$ & 6.9 \\
\hline \multicolumn{4}{|l|}{ Marital status } \\
\hline Married & $61.6(0.8)$ & $59.2(1.3)$ & 61.5 \\
\hline Previously married & $4.8(0.3)^{\mathrm{b}}$ & $6.6(0.5)$ & 6.4 \\
\hline Never married & $33.5(0.7)$ & $34.3(1.2)$ & 32.0 \\
\hline \multicolumn{4}{|l|}{ Age at enlistment, $y$} \\
\hline $17-18$ & $26.3(0.8)$ & $24.0(0.9)^{c}$ & 21.8 \\
\hline $19-20$ & $29.1(0.5)^{b}$ & $26.5(1.1)$ & 26.9 \\
\hline $21-23$ & $23.9(0.5)$ & $24.9(0.8)^{c}$ & 27.4 \\
\hline$\geq 24$ & $20.8(0.7)^{\mathrm{b}}$ & $24.7(1.1)$ & 24.0 \\
\hline \multicolumn{4}{|l|}{ Rank } \\
\hline Lower-ranking enlisted, E1-E4 & $56.9(1.2)^{\mathrm{b}}$ & $43.7(1.6)$ & 43.8 \\
\hline Higher-ranking enlisted, E5-E9 & $32.4(0.8)^{b}$ & $37.9(1.0)$ & 38.0 \\
\hline Officer, W1-5/01-9 & $10.7(1.0)^{\mathrm{b}}$ & $18.4(1.8)$ & 18.2 \\
\hline \multicolumn{4}{|l|}{ No. of deployments } \\
\hline 0 & $32.1(2.1)$ & $31.3(1.8)$ & 31.7 \\
\hline 1 & $34.8(1.7)$ & $31.9(1.7)$ & 31.6 \\
\hline 2 & $19.0(0.6)^{\mathrm{b}}$ & $21.1(0.7)$ & 20.6 \\
\hline$\geq 3$ & $14.2(0.7)$ & $15.7(1.2)$ & 16.1 \\
\hline \multicolumn{4}{|l|}{ Command } \\
\hline Forces Command & $79.2(1.5)^{\mathrm{b}}$ & $53.5(3.6)$ & 50.3 \\
\hline $\begin{array}{l}\text { Area Service Component } \\
\text { Commands }{ }^{\mathrm{d}}\end{array}$ & $4.5(0.8)^{b}$ & $16.1(4.1)$ & 15.5 \\
\hline Special Operations Command & $4.6(0.6)$ & $6.0(1.0)$ & 5.2 \\
\hline Medical Command & $5.6(0.3)^{b}$ & $8.2(0.8)$ & 7.0 \\
\hline $\begin{array}{l}\text { Training and Doctrine } \\
\text { Command }\end{array}$ & $3.8(0.2)^{b}$ & $6.9(0.5)^{c}$ & 10.1 \\
\hline All other commands ${ }^{e}$ & $2.4(1.0)^{b}$ & $9.3(2.7)$ & 11.9 \\
\hline Total No. & 5428 & 5428 & 440369 \\
\hline
\end{tabular}

Abbreviations: E, enlisted rank; 01-9, commissioned officer rank 1-9; STARRS, Study to Assess Risk and Resilience in Servicemembers; W1-5, warrant officer rank 1-5.

a The population data were obtained from the Defense Manpower Data Center Master Personnel and Contingency Tracking System (CTS) for all Regular Army active-duty soldiers exclusive of those in Basic Combat Training or in theater. Results are based on monthly CTS snapshots for the 8-month period between May 2011 and December 2011. The Army STARRS All-Army Survey analysis sample included 5428 participants, and the target population of comparable US Army personnel included 440 369. The estimate of population size is averaged over the 9 months used to generate the population data.

b Significant difference between unweighted and weighted prevalence estimates at the .05 level.

' Significant difference between weighted prevalence estimate and population prevalence at the .05 level.

${ }^{\mathrm{d}}$ Area Commands include Africa (USARAF), Central (USARCENT), North (USARNORTH), South (USARSO), Europe (USAREUR), and Pacific (USARPAC).

e Including Materials Command, all other Service Component Commands, and all other Direct Reporting Units. See http://www .army.mil/info/organization/ for a more detailed description of the US Army Command structure.
The situation was different for externalizing disorders, where $81.7 \%$ of AAS respondents with 30 -day prevalence had first onsets of at least 1 such disorder prior to enlistment. None of the disorder-specific proportions with pre-enlistment onset differed significantly in the AAS vs calibrated NCS-R. This means the higher AAS than NCS-R 30-day prevalence estimates of externalizing disorders were owing equally to cases with pre- and post-enlistment onsets.

\section{Sociodemographic and Army Career Predictors} of 30-Day Disorder Prevalence

Multivariate logistic regression equations predicted each 30day disorder, any internalizing disorder, any externalizing disorder, and any disorder. Only summary results are presented here (Table 3). Detailed results are available on request.
Sex

Women soldiers had significantly elevated odds of any internalizing disorder (1.5) and several individual disorders (MDD, GAD, and PTSD; 1.6-2.6).

\section{Race/Ethnicity}

Although race and ethnicity are significantly associated overall with any disorder $\left(\chi_{3}^{2}=9.4, P=.02\right)$, the only individually significant coefficient was one modestly lower OR among non-Hispanic black than non-Hispanic white individuals (0.7) for IED.

\section{Marital Status}

Although the association of marital status with any disorder is nonsignificant, never-married soldiers had significantly 
Table 2. Estimated 30-Day Prevalence of DSM-IV Internalizing and Externalizing Disorders in Quarters 2 Through 4 of the 2011 Army STARRS AAS and Separately in a Calibrated NCS-R

\begin{tabular}{|c|c|c|c|c|c|c|c|c|}
\hline \multirow[b]{3}{*}{ Variable } & \multicolumn{6}{|c|}{$\%(\mathrm{SE})$} & \multirow{2}{*}{\multicolumn{2}{|c|}{$\begin{array}{l}\text { No. of } \\
\text { 30-Day Cases }\end{array}$}} \\
\hline & \multicolumn{2}{|c|}{ 30-Day Prevalence } & \multicolumn{2}{|c|}{$\begin{array}{c}\text { Proportion of } \\
\text { 30-Day Cases With } \\
\text { Pre-enlistment AAO }\end{array}$} & \multicolumn{2}{|c|}{$\begin{array}{c}\text { Prevalence of } \\
\text { 30-Day Disorders With } \\
\text { Pre-enlistment AAO }\end{array}$} & & \\
\hline & AAS & NCS-R & AAS & NCS-R & AAS & NCS-R & AAS & NCS-R \\
\hline \multicolumn{9}{|l|}{ Internalizing disorders } \\
\hline MDD & $4.8(0.4)^{c}$ & $0.9(0.5)$ & $36.1(3.3)^{c}$ & $77.3(14.0)$ & $1.7(0.2)$ & $0.7(0.5)$ & 295 & 24 \\
\hline BPD & $3.3(0.4)$ & $1.7(1.0)$ & $47.9(2.5)^{c}$ & $84.0(13.0)$ & $1.6(0.3)$ & $1.4(1.0)$ & 213 & 14 \\
\hline GAD & $5.7(0.4)^{c}$ & $2.0(1.5)$ & $34.3(2.7)^{c}$ & $81.3(16.0)$ & $2.0(0.2)$ & $1.6(1.5)$ & 351 & 16 \\
\hline PD & $3.8(0.3)^{c}$ & $0.5(0.2)$ & $27.9(3.4)^{c}$ & $78.1(15.0)$ & $1.0(0.2)^{c}$ & $0.4(0.2)$ & 219 & 15 \\
\hline PTSD & $8.6(0.7)^{c}$ & $0.6(0.2)$ & $29.5(1.7)$ & $20.4(11.8)$ & $2.6(0.3)^{c}$ & $0.1(0.0)$ & 498 & 19 \\
\hline Any internalizing disorder & $15.0(0.7)^{c}$ & $5.3(2.0)$ & $49.6(2.0)^{c}$ & $82.0(8.1)$ & $7.4(0.5)$ & $4.4(1.9)$ & 901 & 84 \\
\hline \multicolumn{9}{|l|}{ Externalizing disorders } \\
\hline ADHD & $7.0(0.6)$ & $3.3(1.6)$ & $100.0(0.0)$ & $100.0(0.0)$ & $7.0(0.6)^{c}$ & $3.3(1.6)$ & 381 & 40 \\
\hline IED & $11.2(0.7)^{\mathrm{c}}$ & $1.7(0.6)$ & $73.4(2.4)$ & $80.2(16.5)$ & $8.2(0.4)^{c}$ & $1.4(0.5)$ & 753 & 30 \\
\hline SUD & $4.8(0.4)$ & $2.5(1.1)$ & $37.5(2.5)$ & $63.0(22.3)$ & $1.8(0.2)$ & $1.6(0.7)$ & 284 & 24 \\
\hline Any externalizing disorder & $18.4(0.8)^{c}$ & $7.3(1.9)$ & $81.7(1.4)$ & $84.3(6.6)$ & $15.0(0.6)$ & $6.2(1.8)$ & 1128 & 92 \\
\hline \multicolumn{9}{|l|}{$\begin{array}{l}\text { Total internalizing and } \\
\text { externalizing disorders }\end{array}$} \\
\hline Any of the above disorders & $25.1(0.8)^{c}$ & $11.6(2.5)$ & $76.6(1.5)^{c}$ & $91.2(4.2)$ & $19.2(0.6)^{\mathrm{c}}$ & $10.6(2.6)$ & 1521 & 167 \\
\hline \multicolumn{9}{|l|}{ No. of disorders } \\
\hline 1 & $14.0(0.8)^{c}$ & $10.4(2.4)$ & $69.5(2.5)^{c}$ & $90.4(4.7)$ & $9.7(0.6)$ & $9.4(2.5)$ & 838 & 130 \\
\hline 2 & $4.4(0.4)^{c}$ & $1.0(0.6)$ & $78.7(2.7)^{c}$ & 98.7 (1.4) & $3.5(0.3)^{c}$ & $1.0(0.6)$ & 292 & 27 \\
\hline$\geq 3$ & $6.7(0.7)^{c}$ & $0.2(0.1)$ & $90.1(2.0)^{c}$ & $98.8(1.5)$ & $6.0(0.6)^{c}$ & $0.2(0.1)$ & 391 & 10 \\
\hline
\end{tabular}

Abbreviations: AAO, age at onset; AAS, All-Army Survey; ADHD,

attention-deficit/hyperactivity disorder; BPD, bipolar disorder; GAD, generalized anxiety disorder; IED, intermittent explosive disorder; MDD, major depressive disorder; NCS-R, National Comorbidity Survey Replication; PD, panic disorder; PTSD, posttraumatic stress disorder; STARRS, Study to Assess Risk and Resilience in Servicemembers; SUD, substance use disorder.

a Proportions of 30 -day cases with pre-accession AAO in the 2 samples and proportions of the total samples with the conjunction of 30-day prevalence

and pre-enlistment AAO.

b The numbers of cases do not equal the products of prevalence times total sample size owing to the fact that prevalence estimates are based on weighted data and the numbers of cases reported are unweighted.

c Significant difference between AAS $(n=5428)$ and NCS-R $(n=1785)$ at the .05 level, 2-sided test.

lower odds than married soldiers of any externalizing (0.7) disorder owing to significantly lower odds of ADHD and IED (0.5-0.6).

\section{Age at Enlistment}

Age at enlistment was significantly associated with any internalizing disorder $\left(X_{2}^{2}=26.8, P<.001\right)$, but not any externalizing disorder $\left(\chi_{2}^{2}=3.1, P=.21\right)$; low odds of MDD, PD, and PTSD (0.4-0.6); and with intermediate age at enlistment (ages 19-23 years).

\section{Rank}

Rank significantly predicted all disorders, with ORs for lowerrank enlisted soldiers significantly elevated vs officers for each aggregate (2.3-3.5), each internalizing disorder other than MDD (2.2-12.0), and each externalizing disorder (2.7-2.8). In addition, odds for virtually all internalizing disorders other than MDD (2.9-6.5) and all externalizing disorders (2.4-3.0) were significantly higher for higher-rank enlisted soldiers than officers.

\section{Deployment History}

Two-thirds of AAS respondents had a history of deployment (31.9\% had 1 deployment, $21.1 \%$ had 2, and $15.7 \%$ had 3 or more).
The number of deployments had a consistently positive monotonic relationship with virtually all disorders and significantly so with 5 (MDD, bipolar disorder, GAD, PTSD, and IED), with ORs in the range of 1.1 to 1.5 for $1,1.2$ to 3.0 for 2 , and 1.7 to 3.8 for 3 or more deployments.

\section{Army Command}

Current Army Command assignment was significantly associated with any internalizing disorder and several individual disorders owing to elevated odds in the Training and Docin the Special Operations Command (PD and PTSD, 0.3-0.5) compared with the Forces Command.

\section{Associations of 30-Day Disorders With Self-Reported Severe Role Impairment}

Reported by $12.8 \%$ of respondents, severe role impairment was substantially more common among soldiers with (31.4\%) than without (6.6\%) DSM-IV mental disorders $\left(\chi_{1}^{2}=79.6, P<.001\right)$. Most respondents with self-reported severe role impairment (61.5\%) had at least one 30-day DSM-IV disorder. The bestfitting model predicting self-reported severe role impairment distinguishes disorders with pre- vs post-enlistment onsets $\left(X_{7}^{2}=16.0, P=.03\right)$, with significant ORs generally higher for trine Command (GAD and PTSD, 1.3-2.2) and decreased odds 
Table 3. Associations of Sociodemographic and Army Career Variables With 30-Day DSM-IV Disorders in Quarters 2 Through 4 in the 2011 Army STARRS All-Army Survey ${ }^{\mathrm{a}}$

\begin{tabular}{|c|c|c|c|}
\hline \multirow[b]{2}{*}{ Variable } & \multicolumn{2}{|c|}{ Odds Ratio (95\% Cl) } & \multirow[b]{2}{*}{ Total Disorders } \\
\hline & Internalizing Disorder & Externalizing Disorder & \\
\hline \multicolumn{4}{|l|}{ Sex } \\
\hline Men & 1.0 & 1.0 & 1.0 \\
\hline Women & $1.5(1.1-2.1)^{\mathrm{b}}$ & $0.9(0.6-1.4)$ & $1.2(0.8-1.7)$ \\
\hline$x_{1}^{2}$ & $7.8^{\mathrm{b}}$ & 0.2 & 0.9 \\
\hline \multicolumn{4}{|l|}{ Race/ethnicity } \\
\hline Non-Hispanic white & 1.0 & 1.0 & 1.0 \\
\hline Non-Hispanic black & $0.8(0.6-1.2)$ & $0.7(0.5-0.9)^{b}$ & $0.7(0.6-1.0)^{\mathrm{b}}$ \\
\hline Hispanic & $0.9(0.7-1.2)$ & $0.9(0.7-1.1)$ & $0.8(0.7-1.0)$ \\
\hline Other & $1.0(0.8-1.4)$ & $1.0(0.7-1.3)$ & $1.0(0.8-1.2)$ \\
\hline$x_{3}^{2}$ & 1.5 & 8.6 & $9.4^{\mathrm{b}}$ \\
\hline \multicolumn{4}{|l|}{ Marital status } \\
\hline Married & 1.0 & 1.0 & 1.0 \\
\hline Previously married & $1.2(0.7-1.9)$ & $0.7(0.5-1.1)$ & $0.9(0.5-1.5)$ \\
\hline Never married & $0.8(0.6-1.1)$ & $0.7(0.6-0.9)^{\mathrm{b}}$ & $0.8(0.7-1.0)$ \\
\hline$x_{2}^{2}$ & 3.2 & $9.2^{\mathrm{b}}$ & 3.8 \\
\hline \multicolumn{4}{|l|}{ Age at enlistment, $y$} \\
\hline $17-18$ & $1.0(0.7-1.4)$ & $1.3(0.9-1.9)$ & $1.2(0.9-1.8)$ \\
\hline $19-20$ & $0.7(0.6-0.9)^{b}$ & $1.2(0.9-1.5)$ & $1.0(0.8-1.2)$ \\
\hline $21-23$ & $0.6(0.4-0.8)^{b}$ & $1.2(0.9-1.7)$ & $0.9(0.7-1.2)$ \\
\hline$\geq 24$ & 1.0 & 1.0 & 1.0 \\
\hline$x_{3}^{2}$ & $26.8^{\mathrm{b}}$ & 3.1 & $8.1^{\mathrm{b}}$ \\
\hline \multicolumn{4}{|l|}{ Rank } \\
\hline $\begin{array}{l}\text { Lower-ranking enlisted, } \\
\text { E1-E4 }\end{array}$ & $3.5(2.4-5.2)^{\mathrm{b}}$ & $2.3(1.5-3.5)^{\mathrm{b}}$ & $2.6(2.1-3.4)^{\mathrm{b}}$ \\
\hline $\begin{array}{l}\text { Higher-ranking enlisted, } \\
\text { E5-E9 }\end{array}$ & $2.9(2.1-3.9)^{\mathrm{b}}$ & $2.3(1.6-3.2)^{b}$ & $2.4(1.8-3.2)^{b}$ \\
\hline Officer, W1-5/01-9 & 1.0 & 1.0 & 1.0 \\
\hline$x_{2}^{2}$ & $52.8^{\mathrm{b}}$ & $22.0^{\mathrm{b}}$ & $58.5^{\mathrm{b}}$ \\
\hline$x_{1}^{2}$ & 1.7 & 0.0 & 0.7 \\
\hline \multicolumn{4}{|l|}{ No. of Deployments } \\
\hline 0 & 1.0 & 1.0 & 1.0 \\
\hline 1 & $1.3(1.0-1.8)$ & $1.1(0.8-1.5)$ & $1.2(0.9-1.5)$ \\
\hline 2 & $2.1(1.5-3.0)^{\mathrm{b}}$ & $1.4(1.0-1.9)^{\mathrm{b}}$ & $1.7(1.3-2.4)^{\mathrm{b}}$ \\
\hline$\geq 3$ & $2.5(1.8-3.4)^{b}$ & $1.5(1.0-2.1)^{b}$ & $1.8(1.5-2.2)$ \\
\hline$x_{3}^{2}$ & $40.8^{\mathrm{b}}$ & 4.8 & $32.5^{\mathrm{b}}$ \\
\hline \multicolumn{4}{|l|}{ Command } \\
\hline Forces Command & 1.0 & 1.0 & 1.0 \\
\hline $\begin{array}{l}\text { Area Service Component } \\
\text { Commands }^{c}\end{array}$ & $1.1(0.8-1.5)$ & $0.9(0.4-1.7)$ & $1.0(0.7-1.4)$ \\
\hline $\begin{array}{l}\text { Special Operations } \\
\text { Command }\end{array}$ & $0.4(0.2-0.9)^{\mathrm{b}}$ & $0.7(0.4-1.4)$ & $0.6(0.3-1.1)$ \\
\hline Medical Command & $1.4(0.9-2.1)$ & $0.8(0.5-1.2)$ & $1.1(0.7-1.5)$ \\
\hline $\begin{array}{l}\text { Training and Doctrine } \\
\text { Command }\end{array}$ & $1.3(1.0-1.8)$ & $1.3(1.0-1.6)^{\mathrm{b}}$ & $1.2(1.0-1.4)$ \\
\hline All other Commands ${ }^{d}$ & $1.3(0.9-1.9)$ & $1.2(0.7-2.1)$ & $1.3(0.8-2.1)$ \\
\hline$\chi_{5}^{2}$ & $14.0^{\mathrm{b}}$ & 8.2 & 6.8 \\
\hline
\end{tabular}

Abbreviation: STARRS, Study to Assess Risk and Resilience in Servicemembers.

a Based on a series of multivariate logistic regression equations with all the previously mentioned predictors in the same model. $\mathrm{N}=5428$.

b Significant at the .05 level, 2-sided test.

c The complete set of Area Commands includes Africa (USARAF), Central (USARCENT), North (USARNORTH), South (USARSO), Europe (USAREUR), and Pacific (USARPAC).

${ }^{\mathrm{d}}$ Including Materials Command, all other Service Component Commands, and all other Direct Reporting Units. See http://www .army.mil/info/organization/ for a complete description of the US Army Command structure. the former than latter (Table 4). Global interactions were significantly subadditive for the number of pre-enlistment $\left(X_{2}^{2}=12.6, P=.002\right)$ and post-enlistment $\left(X_{2}^{2}=6.6, P=.04\right)$ onset disorders, meaning that the ORs for comorbid disorders were significantly less than the products of the ORs reported in Table 4 for component disorders.
The PARPs based on the best-fitting model were $21.7 \%$ for 30-day disorders with pre-enlistment onsets, $24.3 \%$ for 30 day disorders with post-enlistment onsets, and $43.4 \%$ for all 30-day disorders. The latter estimate was smaller than the sum of the first 2 estimates because the effects of pre-enlistment disorders were partially mediated through post-enlistment dis- 
Table 4. Associations of 30-Day DSM-IV Disorders Having Preand Post-enlistment Ages at Onset With Severe Role Impairment in Quarters 2 Through 4 of the 2011 Army STARRS All-Army Survey ${ }^{\mathrm{a}, \mathrm{b}}$

\begin{tabular}{|c|c|c|}
\hline \multirow[b]{2}{*}{ Disorder } & \multicolumn{2}{|c|}{ Odds Ratio $(95 \% \mathrm{Cl})$} \\
\hline & $\begin{array}{l}\text { Disorders With } \\
\text { Pre-enlistment } \\
\text { Onsets } \\
\end{array}$ & $\begin{array}{c}\text { Disorders With } \\
\text { Post-enlistment } \\
\text { Onsets }\end{array}$ \\
\hline \multicolumn{3}{|c|}{ Internalizing disorders } \\
\hline MDD & $11.4(4.7-27.9)^{c}$ & $7.7(2.8-21.1)^{c}$ \\
\hline BPD & $7.0(2.7-18.1)^{c}$ & $3.8(1.8-7.8)^{c}$ \\
\hline GAD & $5.4(2.7-10.9)^{c}$ & $1.5(0.8-2.7)^{c}$ \\
\hline PD & $3.2(1.3-7.9)^{c, d}$ & $1.6(0.9-2.9)$ \\
\hline PTSD & $1.4(0.7-2.9)$ & $1.8(1.3-2.7)^{c}$ \\
\hline \multicolumn{3}{|c|}{ Externalizing disorders } \\
\hline ADHD & $2.3(1.3-3.9)^{c}$ & \\
\hline IED & $1.6(1.2-2.1)^{c}$ & $1.8(1.0-3.4)$ \\
\hline SUD & $2.5(1.1-5.6)^{c}$ & $2.7(1.6-4.5)^{c}$ \\
\hline \multicolumn{3}{|c|}{$\begin{array}{l}\text { No. of internalizing and } \\
\text { externalizing disorders }\end{array}$} \\
\hline 2 & $0.3(0.2-0.6)^{c}$ & \\
\hline$\geq 3$ & $0.2(0.1-0.6)^{c}$ & \\
\hline$x_{8 / 7}^{2}$ & $131.8^{\mathrm{c}}$ & $123.8^{c}$ \\
\hline$x_{2}^{2}$ & $12.6^{c}$ & \\
\hline
\end{tabular}

Abbreviations: ADHD, attention-deficit/hyperactivity disorder; BPD, bipolar disorder; GAD, generalized anxiety disorder; IED, intermittent explosive disorder; MDD, major depression; PD, panic disorder; PTSD, posttraumatic stress disorder; STARRS, Study to Assess Risk and Resilience in Servicemembers; SUD, substance use disorder.

${ }^{\mathrm{a}} \mathrm{N}=5428$.

${ }^{\mathrm{b}}$ Based on a multivariate logistic regression equation controlling for the sociodemographic and Army career variables in Table 3.

c Significant at the .05 level, 2-sided test.

d Significantly different from the odds ratio for disorders with post-enlistment onset.

orders. Consistent with this mediation, the PARP for preenlistment disorders was $32.9 \%$ in a model that did not control post-enlistment disorders vs $21.7 \%$ in the model that included these controls.

\section{Discussion}

Exclusions of deployed soldiers and those in basic training limited generalizability. The low response rate limited external validity despite the lack of evidence of substantial sample bias. ${ }^{18}$ In addition, respondents might have underreported mental disorders, ${ }^{33}$ although methodological studies show this bias is reduced by using the confidential self-administration procedures used here. ${ }^{34,35}$

Within the context of these limitations, AAS 30-day DSM-IV disorders appeared to be more prevalent than among sociodemographically matched civilians owing largely to postenlistment internalizing disorders and both pre- and postenlistment externalizing disorders. The high pre-enlistment externalizing disorders presumably reflected selection processes in the current all-volunteer Army, although the higher prevalence of disorders in the AAS than civilian sample has to be interpreted with caution despite efforts to calibrate the
NCS-R owing to incomplete understanding of selection factors into Army service. Inconsistent results have been reported in previous studies attempting to compare civilian and military prevalence estimates using less rigorous calibration methods. ${ }^{36,37}$ It is also noteworthy that mental disorders predict early attrition ${ }^{38}$ and might influence promotion and deployment, ${ }^{39}$ leading to uncertainties in interpreting associations of those variables with disorders.

To our knowledge, although no previous US Army epidemiological survey estimated the prevalence of the same disorders as the AAS, the $25.1 \%$ overall 30 -day AAS prevalence estimate was close to the $19.5 \%$ estimate for a similar set of disorders in the Millennium Cohort Study. ${ }^{40}$ It is more difficult to compare disorder-specific AAS prevalence estimates with previous surveys owing to variation in samples and measures, but useful comparisons can be gleaned from 3 recent state-of-the-art reviews on military MDD, ${ }^{41} \mathrm{PTSD},{ }^{42}$ and SUD. ${ }^{43}$ The MDD review found a relatively stable prevalence estimate across 25 US Army surveys, with median prevalence (4.4\%) similar to the $4.8 \%$ AAS estimate. ${ }^{41}$ In comparison, the PTSD review found wide variation in prevalence estimates (2.2\%-17.3\%) across surveys of Operation Enduring Freedom/Operation Iraqi Freedom/Operation New Dawn servicemembers. ${ }^{42}$ The $8.6 \%$ AAS PTSD prevalence estimate was at the median of this range, presumably reflecting the AAS inclusion of never-deployed soldiers (who had low PTSD prevalence) and noncoverage of the National Guard and Army Reserve (found in other surveys to have high PTSD prevalence). Finally, the SUD review focused on heavy substance use rather than abuser dependence. ${ }^{44}$ Nor did most previous military surveys study bipolar disorder, GAD, PD, ADHD, or IED, despite 2 of these disorders (ADHD and IED) being among the most common disorders considered here.

That most AAS 30-day DSM-IV disorders had preenlistment onsets should not be surprising given early mental disorder AAO in the general population. ${ }^{13,14}$ That most 30day internalizing disorders with pre-enlistment onsets had comparable prevalence with calibrated civilian estimates suggests that the high AAS 30-day prevalence of internalizing disorders was largely owing to elevated onset risk after enlistment. The situation is different for externalizing disorders, although where pre-enlistment onset in the AAS is much higher than in the civilian sample, suggesting that early-onset externalizing disorders are associated with joining and/or remaining in the Army. Implications of these findings for recruitment are unclear because the Army already screens for emotional problems in pre-enlistment health examinations. However, knowledge that new recruits have high externalizing disorder rates (even if denied in recruitment interviews) might be useful to the Army in developing targeted outreachintervention programs for new soldiers such as interventions for $\mathrm{ADHD}^{45,46}$ and for problems with anger management. 47,48

Results from the AAS regarding sociodemographic and Army career predictors are mostly consistent with previous studies in finding higher rates of internalizing disorders among women than men, ${ }^{49,50}$ somewhat lower rates of IED among non-Hispanic black than white individuals, ${ }^{40,51,52}$ weak associations with age at enlistment, ${ }^{53,54}$ strong inverse associa- 
tions of prevalence with rank, ${ }^{40,44}$ and positive associations of prevalence with number of deployments. ${ }^{55,56}$ However, 3 of these associations warrant brief comment.

First, sex differences in AAS prevalence estimates, consistent with other military surveys, ${ }^{44}$ were smaller than in civilian surveys, ${ }^{49,57-59}$ possibly reflecting differential selection of women into Army service, narrowing of sex differences in military roles, ${ }^{60}$ or sex differences in psychological reactions to military stressors. ${ }^{61,62}$ These possibilities deserve further study in light of the increasing role of women in the military.

Second, the finding that never-married soldiers had somewhat lower prevalence than married soldiers ${ }^{63}$ and absence of higher prevalence among previously married than married soldiers ${ }^{64,65}$ were inconsistent with general-population studies. This might be owing to unique stressors faced by military marriages (frequent moves, deployments, and rules and regulations). ${ }^{66}$ Further analysis is needed to investigate this possibility and to determine whether, as with civilians, effects of marriage might differ by sex ${ }^{67}$ and be related as much to quality duration as to marriage per se. ${ }^{68}$

Third, although the low disorder prevalence in Special Operations Command was broadly consistent with evidence of hyperresilience to stress among Special Operations soldiers, ${ }^{69,70}$ the ethic of stoicism in Special Operations culture ${ }^{71}$ might have led Special Operations survey respondents to underreport emotional problems. ${ }^{55}$ In comparison, we are unaware of previous research that documented elevated mental disorder prevalence in Training and Doctrine Command.
Finally, the finding that 30-day DSM-IV disorders were strong predictors of self-reported severe role impairments was broadly consistent with evidence that mental disorders are highly impairing. ${ }^{72,73}$ The $43.4 \%$ PARP is considerably higher than in civilian surveys, although presumably reflecting Army recruitment-retention practices that reduce impairing physical disorders. That PARP is higher for pre-enlistment than postenlistment mental disorders is consistent with evidence that early AAO is associated with increased mental disorder severity. ${ }^{74,75}$

\section{Conclusions}

Although we know of no previous studies of pre- vs postenlistment disorders, evidence exists for associations of childhood stresses ${ }^{76}$ and mental disorders ${ }^{77,78}$ with poor soldier functioning, lending indirect support to the results reported here. It would be possible to expand future recruitment screening efforts to include self-reports about these pre-enlistment risk factors, but the inability to obtain objective confirmation of these self-reports could undercut the value of such efforts. Another possibility would be to build outreach and treatment programs for new soldiers based on these research findings aimed at attracting soldiers with known pre-enlistment risk factors for targeted interventions, with pre-enlistment mental disorders included in this set of risk factors.

\section{ARTICLE INFORMATION}

Accepted for Publication: December 3, 2013.

Published Online: March 3, 2014.

doi:10.1001/jamapsychiatry.2014.28.

Author Affiliations: Department of Health Care Policy, Harvard Medical School, Boston, Massachusetts (Kessler, Hwang, Petukhova, Sampson, Zaslavsky); National Institute of Mental Health, Bethesda, Maryland (Colpe, Schoenbaum) University of Michigan, Institute for Social Research, Ann Arbor (Heeringa); Department of Psychology, Harvard College, Cambridge, Massachusetts (Nock); Departments of Psychiatry and Family and Preventive Medicine, University of California-San Diego, La Jolla, and VA San Diego Healthcare System, San Diego, California (Stein): Center for the Study of Traumatic Stress, Department of Psychiatry, Uniformed Services University School of Medicine, Bethesda, Maryland (Fullerton, Naifeh, Ursano).

Author Contributions: Dr Kessler had full access to all of the data in the study and takes responsibility for the integrity of the data and the accuracy of the data analysis.

Study concept and design: Kessler, Heeringa, Colpe, Naifeh, Schoenbaum, Ursano.

Acquisition of data: Kessler, Heeringa, Schoenbaum, Ursano.

Analysis and interpretation of data: Kessler, Heeringa, Stein, Fullerton, Hwang, Nock, Petukhova, Sampson, Zaslavsky, Ursano. Drafting of the manuscript: Kessler, Colpe, Ursano. Critical revision of the manuscript for important intellectual content: Kessler, Heeringa, Stein,
Fullerton, Hwang, Naifeh, Nock, Petukhova, Sampson, Schoenbaum, Zaslavsky. Statistical analysis: Heeringa, Hwang, Petukhova Sampson, Schoenbaum, Zaslavsky. Obtained funding: Kessler, Heeringa, Nock, Schoenbaum, Ursano. Administrative, technical, and material support: Kessler, Heeringa, Colpe, Fullerton, Naifeh, Nock, Sampson, Schoenbaum, Ursano.

Study supervision: Kessler, Stein, Nock, Sampson, Ursano.

Conflict of Interest Disclosures: In the past 5 years, Dr Kessler has been a consultant for Eli Lilly \& Co, GlaxoSmithKline Inc, Integrated Benefits Institute, Ortho-McNeil-Janssen Scientific Affairs, Pfizer Inc, sanofi-aventis, Shire US Inc, and Transcept Pharmaceuticals Inc, and he has served on advisory boards for Johnson \& Johnson. Dr Kessler received research support for his epidemiological studies over this period from Eli Lilly \& Co, EPI-Q, GlaxoSmithKline, Ortho-McNeil-Janssen Scientific Affairs, sanofi-aventis, Shire US Inc, and Walgreens Co. Dr Kessler owns a $25 \%$ share in DataStat Inc. In the last 3 years, Dr Stein has been a consultant for Healthcare Management Technologies and received research support for pharmacological imaging studies from Janssen. No other disclosures were reported.

Funding/Support: Army STARRS was sponsored by the Department of the Army and funded under cooperative agreement U01MH087981 with the US Department of Health and Human Services, National Institutes of Health, National Institute of Mental Health.
Role of the Sponsor: The sponsors specified the topic in the request for proposal but had no role in the design and conduct of the study; collection, management, analysis, or interpretation of the data; preparation, review, or approval of the manuscript; and decision to submit the manuscript for publication. However, as a cooperative agreement, collaborating scientists appointed to the project by the National Institute of Mental Health (NIMH) (Drs Colpe and Schoenbaum) and Army liaisons/consultants (COL Steven Cersovsky, MD, MPH [USAPHC], and Kenneth Cox, MD, MPH [USAPHC]) participated in the refinement of the study protocol originally proposed by Drs Ursano, Kessler, and Heeringa. Dr Colpe additionally collaborated in the creation of the data collection instruments and supervision of Army STARRS All-Army Study (AAS) data collection, while Dr Schoenbaum collaborated in the acquisition of the administrative data that are linked to AAS survey reports. None of the Army or NIMH collaborators was involved in planning or supervising data analyses for this report, but Drs Colpe and Schoenbaum both read the first draft and offered suggestions for revision. Although a draft of this manuscript was submitted to the Army and NIMH for review and comment prior to submission, this was with the understanding that comments would be no more than advisory.

The Army STARRS Collaborators: The Army STARRS collaborators consist of coprincipal investigators Robert J. Ursano, MD (Uniformed Services University of the Health Sciences) and Murray B. Stein, MD, MPH (University of California-San Diego and VA San Diego Healthcare 
System); site principal investigators Steven Heeringa, PhD (University of Michigan) and Ronald C. Kessler, PhD (Harvard Medical School); National Institute of Mental Health collaborating scientists Lisa J. Colpe, PhD, MPH, and Michael Schoenbaum, $\mathrm{PhD}$; and Army liaisons/consultants COL Steven Cersovsky, MD, MPH (USAPHC), and Kenneth Cox, MD, MPH (USAPHC). Other team members included Pablo A. Aliaga, MA (Uniformed Services University of the Health Sciences); COL David M. Benedek, MD (Uniformed Services University of the Health Sciences); Susan Borja, PhD (National Institute of Mental Health); Gregory G. Brown, PhD (University of California-San Diego); Laura Campbell-Sills, PhD (University of California-San Diego); Catherine L. Dempsey, PhD, MPH (Uniformed Services University of the Health Sciences); Richard Frank, PhD (Harvard Medical School); Carol S. Fullerton, PhD (Uniformed Services University of the Health Sciences); Nancy Gebler, MA (University of Michigan); Robert K. Gifford, PhD (Uniformed Services University of the Health Sciences); Stephen E. Gilman, ScD (Harvard School of Public Health); Marjan G. Holloway, PhD (Uniformed Services University of the Health Sciences); Paul E. Hurwitz, MPH (Uniformed Services University of the Health Sciences); Sonia Jain, PhD (University of California San Diego); Tzu-Cheg Kao, PhD (Uniformed Services University of the Health Sciences); Karestan C. Koenen, PhD (Columbia University); Lisa Lewandowski-Romps, PhD (University of Michigan); Holly Herberman Mash, PhD (Uniformed Services University of the Health Sciences); James E. McCarroll, PhD, MPH (Uniformed Services University of the Health Sciences); Katie A. McLaughlin, PhD (Harvard Medical School); James A. Naifeh, PhD (Uniformed Services University of the Health Sciences); Matthew K. Nock, PhD (Harvard University); Rema Raman, PhD (University of California-San Diego); Nancy A. Sampson, BA (Harvard Medical School); LCDR Patcho Santiago, MD, MPH (Uniformed Services University of the Health Sciences): Michaelle Scanlon, MBA (National Institute of Mental Health); Jordan Smoller, MD, ScD (Harvard Medical School); Nadia Solovieff, PhD (Harvard Medical School); Michael L. Thomas, PhD (University of California-San Diego); and Alan M. Zaslavsky, PhD (Harvard Medical School).

Disclaimer: The content of this article is solely the responsibility of the authors and does not necessarily represent the views of the Department of Health and Human Services, the National Institute of Mental Health, the Department of the Army, or the Department of Defense.

Additional Information: A complete list of Army STARRS publications can be found at http://www.ARMYSTARRS.org.

\section{REFERENCES}

1. Ritchie EC, Benedek D, Malone R, Carr-Malone R. Psychiatry and the military: an update. Psychiatr Clin North Am. 2006;29(3):695-707.

2. Army Medical Surveillance Activity. Relative burdens of selected illnesses and injuries, US Armed Forces, 2001. Med Surveill Monthly Rep. 2002;8(2):24-28

3. Bryan CJ, Hernandez AM, Allison S, Clemans T. Combat exposure and suicide risk in two samples of military personnel. J Clin Psychol. 2013;69(1):64-77.
4. Hoge CW, Castro CA, Messer SC, McGurk D, Cotting DI, Koffman RL. Combat duty in Iraq and Afghanistan, mental health problems, and barriers to care. N Engl J Med. 2004;351(1):13-22.

5. Prigerson HG, Maciejewski PK, Rosenheck RA. Population attributable fractions of psychiatric disorders and behavioral outcomes associated with combat exposure among US men. Am J Public Health. 2002;92(1):59-63.

6. Ursano RJ, Holloway HC, Jones DR, Rodriguez AR, Belenky GL. Psychiatric care in the military community: family and military stressors. Hosp Community Psychiatry. 1989;40(12):1284-1289.

7. Armed Forces Health Surveillance Center (AFHSC). Absolute and relative morbidity burdens attributable to various illnesses and injuries, US Armed Forces, 2010. Med Surveill Monthly Rep. 2012;18(4):2-7.

8. Bryan CJ, Jennings KW, Jobes DA, Bradley JC. Understanding and preventing military suicide. Arch Suicide Res. 2012;16(2):95-110.

9. Cesur R, Sabia JJ, Tekin E. The psychological costs of war: military combat and mental health. J Health Econ. 2013;32(1):51-65.

10. Buddin RJ. Success of First-Term Soldiers: The Effects of Recruitment Practices and Recruit Characteristics. Santa Monica, CA: Rand Corporation; 2005

11. Korb LJ, Duggan SE. An all-volunteer Army? recruitment and its problems. Polit Sci Polit. 2007;40(3):467-471. doi:10.1017 /S1049096507070953.

12. de Girolamo G, Dagani J, Purcell R, Cocchi A, McGorry PD. Age of onset of mental disorders and use of mental health services: needs, opportunities and obstacles. Epidemiol Psychiatr Sci.

2012;21(1):47-57.

13. Kessler RC, Amminger GP, Aguilar-Gaxiola S, Alonso J, Lee S, Ustün TB. Age of onset of mental disorders: a review of recent literature. Curr Opin Psychiatry. 2007;20(4):359-364.

14. McGorry PD, Purcell R, Goldstone $S$, Amminger GP. Age of onset and timing of treatment for mental and substance use disorders: implications for preventive intervention strategies and models of care. Curr Opin Psychiatry. 2011;24(4):301-306

15. Kessler RC, Avenevoli S, Costello J, et al. Severity of 12-month DSM-IV disorders in the National Comorbidity Survey Replication Adolescent Supplement. Arch Gen Psychiatry 2012;69(4):381-389.

16. Kessler RC, Colpe LJ, Fullerton CS, et al. Design of the Army Study to Assess Risk and Resilience in Servicemembers (Army STARRS). Int J Methods Psychiatr Res. 22(4):267-275.

17. American Association for Public Opinion Research. Standard Definitions: Final Dispositions of Case Codes and Outcome Rates for Surveys. Deerfield, IL: American Association for Public Opinion Research; 2009.

18. Kessler RC, Heeringa SG, Colpe LJ, et al Response bias, weighting adjustments, and design effects in the Army Study to Assess Risk and Resilience in Servicemembers (Army STARRS). Int J Methods Psychiatr Res. 2013;22(4):288-302.

19. Heeringa SG, Gebler N, Colpe LJ, et al. Field procedures in the Army Study to Assess Risk and
Resilience in Servicemembers (Army STARRS). Int J Methods Psychiatr Res. 2013;22(4):276-287.

20. Kessler RC, Ustün TB. The World Mental Health (WMH) Survey Initiative Version of the World Health Organization (WHO) Composite International Diagnostic Interview (CIDI). Int J Methods Psychiatr Res. 2004;13(2):93-121.

21. Weathers F, Litz B, Herman D, Huska J, Keane T. The PTSD Checklist (PCL): reliability, validity, and diagnostic utility. Paper presented at: Annual Meeting of the International Society for Traumatic Stress Studies. San Antonio, TX; 1993.

22. Kessler RC, Petukhova M, Zaslavsky AM. The role of latent internalizing and externalizing predispositions in accounting for the development of comorbidity among common mental disorders. Curr Opin Psychiatry. 2011;24(4):307-312.

23. Bray RM, Pemberton MR, Lane ME, Hourani LL, Mattiko MJ, Babeu LA. Substance use and mental health trends among US military active duty personnel: key findings from the 2008 DoD Health Behavior Survey. Mil Med. 2010;175(6):390-399.

24. Kessler RC, Santiago PN, Colpe LJ, et al. Clinical reappraisal of the Composite International Diagnostic Interview Screening Scales (CIDI-SC) in the Army Study to Assess Risk and Resilience in Servicemembers (Army STARRS). Int J Methods Psychiatr Res. 2013;22(4):303-321.

25. First MB, Spitzer RL, Gibbon M, Williams JBW. Structured Clinical Interview for DSM-IV Axis I Disorders, Research Version, Non-patient Edition (SCID-I/NP). New York, NY: Biometrics Research, New York State Psychiatric Institute; 2002.

26. Leon $\mathrm{AC}$, Olfson $\mathrm{M}$, Portera $\mathrm{L}$, Farber $\mathrm{L}$, Sheehan DV. Assessing psychiatric impairment in primary care with the Sheehan Disability Scale. Int J Psychiatry Med. 1997;27(2):93-105.

27. Kessler RC, Merikangas KR. The National Comorbidity Survey Replication (NCS-R): background and aims. Int J Methods Psychiatr Res. 2004;13(2):60-68.

28. Gadermann AM, Gilman SE, McLaughlin KA, et al. Projected rates of psychological disorders and suicidality among soldiers based on simulations of matched general population data. Mil Med. 2012;177(9):1002-1010.

29. SAS Institute Inc. SAS/STAT 9.2 User's Guide. 2nd ed. Cary, NC: SAS Institute Inc; 2009.

30. Rubin DB. Multiple Imputation for Nonresponse in Surveys. New York, NY: John Wiley \& Sons; 1987.

31. Cox C, Li X. Model-based estimation of the attributable risk: a loglinear approach. Comput Stat Data Anal. 2012;56(12):4180-4189.

32. Rothman K, Greenland S. Modern Epidemiology. 2nd ed. Philadelphia, PA: Lippincott Williams \& Wilkins; 1998.

33. Cannell CF, Marquis KH, Laurent A. A summary of studies of interviewing methodology. Vital Health Stat 2. 1977; (69):i-viii, 1-78.

34. Kessler RC, Wittchen $\mathrm{H}-\mathrm{U}$, Abelson JM, et al. Methodological studies of the Composite International Diagnostic Interview (CIDI) in the US National Comorbidity Survey. Int J Methods Psychiatr Res. 1998;7(1):33-55. doi:10.1002/mpr.33. 35. Turner CF, Ku L, Rogers SM, Lindberg LD, Pleck $\mathrm{JH}$, Sonenstein FL. Adolescent sexual behavior, drug use, and violence: increased reporting with 
computer survey technology. Science. 1998;280(5365):867-873.

36. Hoerster KD, Lehavot K, Simpson T, McFall M, Reiber G, Nelson KM. Health and health behavior differences: US military, veteran, and civilian men. Am J Prev Med. 2012;43(5):483-489.

37. Lehavot K, Hoerster KD, Nelson KM, Jakupcak $M$, Simpson TL. Health indicators for military, veteran, and civilian women. Am J Prev Med. 2012;42(5):473-480.

38. Hoge CW, Lesikar SE, Guevara R, et al. Mental disorders among US military personnel in the 1990s: association with high levels of health care utilization and early military attrition. Am J Psychiatry. 2002;159(9):1576-1583.

39. Haley RW. Point: bias from the "healthy-warrior effect" and unequal follow-up in three government studies of health effects of the Gulf War. Am J Epidemiol. 1998;148(4):315-323.

40. Riddle JR, Smith TC, Smith B, et al; Millennium Cohort Study Team. Millennium Cohort: the 2001-2003 baseline prevalence of mental disorders in the US military. J Clin Epidemiol. 2007;60(2):192-201.

41. Gadermann AM, Engel CC, Naifeh JA, et al. Prevalence of DSM-IV major depression among US military personnel: meta-analysis and simulation. Mil Med. 2012;177(8)(suppl):47-59.

42. Hermann BA, Shiner B, Friedman MJ. Epidemiology and prevention of combat-related post-traumatic stress in OEF/OIF/OND service members. Mil Med. 2012;177(8)(suppl):1-6.

43. Sirratt D, Ozanian A, Traenkner B. Epidemiology and prevention of substance use disorders in the military. Mil Med. 2012;177(8)(suppl):21-28.

44. Bray RM, Pemberton MR, Hourani LL, et al. 2008 Department of Defense Survey of Health Related Behaviors Among Active Duty Military Personnel: A Component of the Defense Lifestyle Assessment Program (DLAP). Research Triangle Park, NC: Research Triangle Institute; 2009.

45. Manos MJ. Psychosocial therapy in the treatment of adults with attention-deficit /hyperactivity disorder. Postgrad Med. 2013;125(2):51-64.

46. Moriyama TS, Polanczyk GV, Terzi FS, Faria KM, Rohde LA. Psychopharmacology and psychotherapy for the treatment of adults with ADHD: a systematic review of available meta-analyses. CNS Spectr. 2013;18(6):296-306.

47. Shea MT, Lambert J, Reddy MK. A randomized pilot study of anger treatment for Iraq and Afghanistan veterans. Behav Res Ther. 2013;51(10):607-613.

48. Williams A, Hagerty BM, Andrei AC, Yousha SM Hirth RA, Hoyle KS. STARS: strategies to assist navy recruits' success. Mil Med. 2007;172(9):942-949.

49. Eaton NR, Keyes KM, Krueger RF, et al. An invariant dimensional liability model of gender differences in mental disorder prevalence: evidence from a national sample. J Abnorm Psychol. 2012;121(1):282-288

50. Rona RJ, Fear NT, Hull L, Wessely S. Women in novel occupational roles: mental health trends in the UK Armed Forces. Int J Epidemiol. 2007;36(2):319-326.

51. Harris KM, Edlund MJ, Larson S. Racial and ethnic differences in the mental health problems and use of mental health care. Med Care. 2005:43(8):775-784.

52. Huang B, Grant BF, Dawson DA, et al. Race-ethnicity and the prevalence and co-occurrence of Diagnostic and Statistical Manual of Mental Disorders, Fourth Edition, alcohol and drug use disorders and axis I and II disorders: United States, 2001 to 2002. Compr Psychiatry. 2006;47(4):252-257.

53. Kolb D, Gunderson EK. A longitudinal study of health risks associated with alcohol abuse in young navy men. Drug Alcohol Depend. 1981;8(2):131-141.

54. Larson GE, Booth-Kewley S, Highfill-McRoy RM, Young SY. Prospective analysis of psychiatric risk factors in marines sent to war. Mil Med. 2009;174(7):737-744

55. Hing M, Cabrera J, Barstow C, Forsten R. Special operations forces and incidence of post-traumatic stress disorder symptoms. J Spec Oper Med. 2012;12(3):23-35.

56. Reger MA, Gahm GA, Swanson RD, Duma SJ. Association between number of deployments to Iraq and mental health screening outcomes in US Army soldiers. J Clin Psychiatry. 2009;70(9):1266-1272.

57. Kessler RC, Adler L, Barkley R, et al. The prevalence and correlates of adult ADHD in the United States: results from the National Comorbidity Survey Replication. Am J Psychiatry. 2006;163(4):716-723.

58. Kessler RC, Coccaro EF, Fava M, Jaeger $S$, Jin R Walters $\mathrm{E}$. The prevalence and correlates of DSM-IV intermittent explosive disorder in the National Comorbidity Survey Replication. Arch Gen Psychiatry. 2006;63(6):669-678.

59. Zilberman ML, Tavares H, Blume SB, el-Guebaly $\mathrm{N}$. Substance use disorders: sex differences and psychiatric comorbidities. Can J Psychiatry. 2003:48(1):5-13.

60. Wilhelm K, Parker G, Hadzi-Pavlovic D. Fifteen years on: evolving ideas in researching sex differences in depression. Psychol Med. 1997;27(4):875-883

61. Hoge CW, Clark JC, Castro CA. Commentary: women in combat and the risk of post-traumatic stress disorder and depression. Int J Epidemiol. 2007;36(2):327-329.

62. Vogt DS, Pless AP, King LA, King DW Deployment stressors, gender, and mental health outcomes among Gulf War I veterans. J Trauma Stress. 2005;18(2):115-127.

63. Simon RW. Revisiting the relationships among gender, marital status, and mental health. AJS. 2002;107(4):1065-1096.
64. Breslau J, Miller $\mathrm{E}$, Jin $\mathrm{R}$, et al. A multinational study of mental disorders, marriage, and divorce. Acta Psychiatr Scand. 2011;124(6):474-486.

65. Hughes ME, Waite LJ. Marital biography and health at mid-life. J Health Soc Behav. 2009;50(3):344-358.

66. Drummet AR, Coleman M, Cable S. Military families under stress: implications for family life education. Fam Relat. 2003;52(3):279-287. doi:10.1111/j.1741-3729.2003.00279.x.

67. Scott KM, Wells JE, Angermeyer M, et al. Gender and the relationship between marital status and first onset of mood, anxiety and substance use disorders. Psychol Med. 2010;40(9):1495-1505.

68. Gibb SJ, Fergusson DM, Horwood LJ. Relationship duration and mental health outcomes: findings from a 30-year longitudinal study. $\mathrm{Br} \mathrm{J}$ Psychiatry. 2011;198(1):24-30.

69. Morgan CA III, Wang S, Mason J, et al. Hormone profiles in humans experiencing military survival training. Biol Psychiatry. 2000;47(10):891-901.

70. Vythilingam M, Nelson EE, Scaramozza M, et al. Reward circuitry in resilience to severe trauma: an fMRI investigation of resilient special forces soldiers. Psychiatry Res. 2009;172(1):75-77.

71. Froede K. Underneath the unconventional: philosophies \& paradigms of special operations forces clinical science. J Spec Oper Med. 2011:11(3):56-60.

72. Druss BG, Hwang I, Petukhova M, Sampson NA Wang PS, Kessler RC. Impairment in role functioning in mental and chronic medical disorders in the United States: results from the National Comorbidity Survey Replication. Mol Psychiatry. 2009;14(7):728-737.

73. Ormel J, Petukhova M, Chatterji S, et al. Disability and treatment of specific mental and physical disorders across the world. Br J Psychiatry. 2008;192(5):368-375.

74. Clark DB, Jones BL, Wood DS, Cornelius JR. Substance use disorder trajectory classes: diachronic integration of onset age, severity, and course. Addict Behav. 2006:31(6):995-1009.

75. Kessler RC, Keller MB, Wittchen HU. The epidemiology of generalized anxiety disorder Psychiatr Clin North Am. 2001;24(1):19-39.

76. Cabrera OA, Hoge CW, Bliese PD, Castro CA, Messer SC. Childhood adversity and combat as predictors of depression and post-traumatic stress in deployed troops. Am J Prev Med. 2007;33(2):77-82.

77. Ames GM, Cunradi CB, Moore RS. Alcohol, tobacco, and drug use among young adults prior to entering the military. Prev Sci. 2002;3(2):135-144.

78. Macmanus D, Dean K, Iversen AC, et al. Impact of pre-enlistment antisocial behaviour on behavioural outcomes among UK military personnel. Soc Psychiatry Psychiatr Epidemiol. 2012:47(8):1353-1358. 22038568 